REVISTA X, Curitiba, volume 14, n.4,p.41-64, 2019

\title{
A ABORDAGEM DO DISCURSO CONSERVADOR SOBRE POLÍTICAS DE AÇÕES AFIRMATIVAS PARA NEGROS NAS UNIVERSIDADES POR UMA PERSPECTIVA DE ANÁLISE BAKHTINIANA
}

The conservative speech approach on affirmative actions for blacks in the universities by means a bakhtinian analysis perspective

Daiane Franciele Morais de QUADROS (UEPG) ${ }^{1}$

\begin{abstract}
RESUMO: O presente estudo aborda a temática do discurso conservador sobre políticas de ações afirmativas para negros nas universidades. O objetivo central deste artigo consiste em investigar quais são os principais tipos de discursos, na cosmovisão político ideológica conservadora, que são opositores às políticas de cotas nas universidades públicas brasileiras. Para tanto, o presente estudo se respalda na perspectiva teórica da Análise Dialógica do Discurso (ADD), no Círculo de Bakhtin, Todorov (1989), Bakhtin (2013; 2015; 2016) e Volóchinov (2017) buscando indícios de que não se pode pensar em língua, discursos e ideologias sem observar aspectos sociais, a sociedade e como a língua acaba se tornando instrumento e local de disputas pelo poder. A metodologia deste trabalho foi de cunho qualitativo, a qual demandou em uma busca e análise pautada na ADD e na compreensão sobre as principais características de mídias áudio visuais. A partir disso, trabalhei com a análise de dois vídeos de intelectuais conservadores que foram publicados pela rede social do YouTube. Como resultados constatei que as mídias áudio visuais são formas eficientes de documentação e propagação de discursos em nosso atual contexto tecnológico, bastante utilizados como comunicação social entre grupos, pessoas e quaisquer entidades não relacionadas à mídia televisiva.
\end{abstract}

PALAVRAS-CHAVE: ações afirmativas para negros; Análise Dialógica do Discurso; discurso conservador; gênero textual vídeo.

\begin{abstract}
This paper approach the conservative speeches on affirmative actions for blacks in the universities. The main aim of this paper investigate which are the main kind of speeches, in the conservative ideological political worldview, which are opponents at affirmative actions in the Brazilian public universities. Therefore, this study is supported by theoretical perspective of the Dialogic Discourse Analysis (DDA), by Bakhtin Circle, Todorov (1989), Bakhtin $(2013 ; 2015 ; 2016)$ and Volóchinov (2017) searching indications of that you may not think of language, speeches and ideologies without looking social aspects, the society an how the language becomes instrument and place of disputes over power. The methodology of this paper was qualitative, which required a search and analysis based on DDA and on the understanding about the main features of audiovisual medias. From here onwards, I working with the analysis of two videos of conservative intellectuals which went published by YouTube social network. As results I noticed that the audiovisual medias are
\end{abstract}

\footnotetext{
${ }^{1}$ Mestre em Linguagem, Identidade e Subjetividade pela Universidade Estadual de Ponta Grossa, UEPG, Brasil.
} 
efficient ways of documentation and propagation of speeches in our current technological context, quite used as social communication among groups, people and whatsoever organizations not related television media.

KEYWORDS: affirmative actions for blacks; Dialogic Discourse Analysis; conservative speech; textual genre video.

\section{INTRODUÇÃO}

Antes de entrar no assunto principal que será descrito por esta pesquisa, início este artigo já realizando uma observação: o objeto de estudo deste trabalho, na atualidade, é um dos assuntos mais polêmicos no Brasil, e até certo ponto, pode ser considerado até mesmo "perigoso de ser abordado". Aliás, discutir o tema política no Brasil ao longo da nossa história sempre foi um assunto bastante problemático e espinhoso. Por essa razão, reconheço que assim como a Análise do Discurso explica, este texto, assim como qualquer outro texto, poderá causar inúmeros e imprevisíveis efeitos na reação dos futuros leitores/interlocutores. Uma vez que este trabalho é uma pesquisa desenvolvida no campo da Análise do Discurso, a qual é uma área da Linguística que propõe instigar a criticidade e estimular a subjetividade diante da abordagem de assuntos que podem ser considerados verdadeiros "tabus" em nossa sociedade.

Portanto, reconheço que este estudo, devido à polêmica e ao grau de complexidade do objeto de estudo, poderá ser (in)compreendido, criticado, o leitor poderá concordar ou não com o raciocínio desenvolvido durante as análises e etc. Algo que em meu ponto de vista é excelente, principalmente quando o leitor contesta ou questiona o que está sendo discutido. Uma vez que, o presente estudo buscou abordar a temática: discurso e opiniões conservadoras sobre políticas de ações afirmativas para estudantes negros nas universidades brasileiras. O objetivo principal deste trabalho resume-se em investigar quais são os principais tipos de discursos, na cosmovisão político ideológica conservadora, que são opositores às políticas de cotas nas universidades públicas brasileiras.

Como objetivos específicos, o presente trabalho comprometeu-se em desenvolver um percurso, o qual buscou: pesquisar, pela rede do YouTube, canais de posicionamento político ideológico conservadores que abordaram a cosmovisão conservadora a respeito das políticas de cotas nas universidades; analisar as opiniões e quais são os tipos de discursos proclamados por alguns intelectuais conservadores a respeito do assunto. E por último, produzir elementos para contribuir para a reflexão 
sobre a medida em que esses conteúdos associados a crescente popularização de canais conservadores no YouTube, aplicados ao contexto brasileiro, estão influenciando nas subjetividades e construções de opiniões da população brasileira a respeito do assunto políticas de cotas nas universidades.

Não é de hoje que venho abordando o assunto políticas de ações afirmativas na universidade pública, pois durante minha trajetória de pesquisa na pós-graduação, desde o mestrado e posteriormente na especialização interdisciplinar, a qual emendei logo após a conclusão do mestrado, já venho discutindo sobre o tema discursos e formações de opiniões sobre o polêmico debate a respeito de políticas de cotas raciais em nossas universidades ${ }^{2}$.

Pois, também devido à polêmica, ao grau de complexidade do debate que envolve o tema políticas de ações afirmativas, e principalmente, as políticas cotas nas universidades públicas brasileiras, desde que as mesmas foram implementadas em nosso sistema educacional de nível superior. Assim como é em qualquer campo científico ou área acadêmica, não importa quantas pesquisas, dissertações, teses, trabalhos de conclusão de curso e etc. sejam desenvolvidos, sempre existirão e surgirão ainda mais lacunas a serem preenchidas a respeito desse tema.

Um exemplo disso, é que como consequência de meus trabalhos anteriores, surgiram ainda mais questionamentos que não puderam ser contestados, pois a medida em que minhas pesquisas desenvolvidas durante a pós-graduação, sobretudo no mestrado, alguns assuntos, como: a influência da mídia brasileira, espaços virtuais e formação de opiniões sobre políticas de cotas em Instituições de Ensino Superior (IES) não puderam ser discutidos, para assim não fugir muito do foco, objetivos e prazo de desenvolvimento do estudo. Por essa razão, será proposto neste artigo me aprofundar um pouco mais nos assuntos mencionados, por meio de uma cosmovisão de Análise do

\footnotetext{
${ }^{2}$ A dissertação de mestrado que originou o presente estudo pode ser consultada no Catálogo de Teses e Dissertações da Capes, nos acervos digitais da biblioteca da Universidade Estadual de Ponta Grossa e do Programa de Pós-Graduação em Estudos da Linguagem da UEPG, por meio da seguinte referência bibliográfica: QUADROS, D. F. M de. Discurso e poder: um olhar acerca das ações afirmativas na UEPG em 2013. 2017, 231f. Dissertação (Mestrado em Estudos da Linguagem) - Universidade Estadual de Ponta Grossa, Ponta Grossa, PR, 2017.

Há também outras publicações dos resultados dessa pesquisa, as quais antecedem a pesquisa atual: QUADROS, D. F. M. de; JOVINO, I. da S. A cartilha informativa sobre as políticas de cotas na UEPG publicada em 2016: um olhar por meio da análise crítica do discurso. Cadernos Discursivos. Catalão, GO, v. 1 n. 1, p. 76-98, 2017.

QUADROS, D. F. M de. Discurso e poder: uma análise das estratégias linguísticas e discursivas no polêmico debate sobre a lei de cotas. Revista Humanidades e Inovação. Palmas, TO, v. 5, n. 4, jul. p. 24-36, 2018.
} 
Discurso, com ênfase em uma perspectiva bakhtiniana dialógica, ou seja, Análise do Discurso Dialógica.

A metodologia será de base qualitativa, exploratória e descritiva, a qual também se respaldará na ADD como proposta metodológica, para analisar dois vídeos publicados em canais do YouTube, os quais apresentam conteúdo da temática política conservadora, onde intelectuais como Luiz Felipe Pondé e Olavo de Carvalho discutem sobre porque são contra as políticas de cotas raciais no ensino superior brasileiro.

Nas considerações finais serão apresentadas algumas conclusões baseadas em tudo o que será discutido durante a fundamentação teórica e a prática da metodologia, buscando avaliar e expor algumas considerações acerca dos resultados obtidos neste trabalho.

\section{FUNDAMENTAÇÃO TEÓRICA}

De acordo com a obra de Eni Orlnadi (2002), autora que foi uma das pioneiras da Análise do Discurso no Brasil, o campo da AD emergiu e estabilizou-se entre os estudos discursivos em um período e espaço, nos quais a Linguística se identificava com a Filosofia e as Ciências Sociais em modo geral. A partir disso, é pertinente assimilar a respeito das noções básicas sobre AD, que Análise do Discurso adveio de três raízes, campos teóricos distintos entre si: o Marxismo, a Psicanálise e a Linguística, Orlandi (2002). Cada uma dessas áreas das ciências humanas à sua maneira contribuíram para que o campo da Análise do Discurso e seus conceitos gerais, independentemente de seu eixo teórico, adquirisse o formato epistemológico que possui hoje.

Portanto, de acordo com Eni Orlandi (2002), a herança da Linguística manifestada na AD reflete-se no fato de a Análise do Discurso tentar explicar que a relação linguagem/pensamento/mundo não pode admitir apenas uma única e incontestável linha de raciocínio, interpretação, leitura de mundo. A herança da Filosofia com ênfase no Marxismo, para a AD, manifesta-se no fato de a história apreciar o simbólico, ou seja, os fatos requererem sentidos. A característica da Psicanálise encontra-se na noção básica de que o sujeito discursivo é movido pela ideologia e pelo inconsciente.

A presente pesquisa é orientada por essas três características gerais da Análise do Discurso, pois os objetivos específicos e os principais estabelecidos por este estudo 
buscam comtemplar uma diversidade de possibilidades de leitura e interpretação, ao se analisar os elementos mundo/linguagem e pensamento.

É pertinente destacar que a presente pesquisa também reflete a característica filosófica da $\mathrm{AD}$, e não puramente o lado filosófico e político do Marxismo, pois estamos discutindo uma teoria situada no campo da linguagem que ao se originar recebeu influências do Marxismo. Mas, aqui quando se busca estabelecer sentidos para os fatos analisados, como a política, por exemplo, é defendida a ideia de que tudo deve ser questionado e discutido, como: articulação da linguagem, ideologias conservadoras, progressistas, liberais e entre outras, as subjetividades dos sujeitos independentemente do posicionamento político e etc., pois os fatos sociais devem ser questionados, de tal modo que, este estudo ao ser de cunho linguístico, busca analisar criticamente as articulações dos discursos manifestados nos vídeos analisados de forma dialógica, buscando compreender e identificar quais são as ideologias manifestadas pelo inconsciente dos sujeitos.

Segundo Eni Orlandi (2002), apesar de a Análise do Discurso ser uma ciência da linguagem bastante recente, pois a mesma emergiu entre os estudos discursivos para o mundo em meados da década de 1960, isso não foi motivo para que a mesma, em âmbito mundial, se expandisse e originasse outras vertentes teóricas. O estudo que Paula (2013) afirma que no Brasil existem vários tipos de "Análises do Discursos" (ADs), que a autora prefere referir-se no plural, em virtude da diversidade de influências e amplitude de abordagens que aqui são desenvolvidas. Pois conforme a autora, os próprios analistas dos discursos em seus trabalhos pautam-se em diferentes perspectivas de ADs, como a AD Francesa, a Análise Crítica do Discurso (ACD), ADD, as semióticas de linha inglesa e norte-americana, russa e francesa, e as teorias enunciativas de Benveniste. Por essa razão, Paula (2013) argumenta que seria mais apropriado que nos referíssemos à $\mathrm{AD}$ sempre no plural.

Observando essa diversidade nesse campo de estudos, buscarei desenvolver neste trabalho um dos olhares citados sobre a Análise do Discurso, a Análise Dialógica do Discurso, não somente, porque precisei dialogar com os parâmetros e o contexto nos quais o presente trabalho foi desenvolvido. Mas também, porque "afinal, a teoria não deve ser usada como camisa de força que leve a leituras analíticas equivocadas porque forçadas ou porque o analista possui empatia por ela" (PAULA, 2013, p. 242). Uma vez, que independe do tipo de análise de discurso que o analista pretenda desenvolver, o 
mesmo, inconscientemente ou não, sempre manifestará alguma contribuição do Círculo de Bakhtin expressa nos estudos discursivos.

Vale salientar que em minhas outras abordagens do objeto de estudo que proponho problematizar neste artigo, segui outra perspectiva de Análise do Discurso, a denominada Análise Crítica do Discurso de linha inglesa. Mas, ao aprofundar meus estudos sobre ADs, descobri que de modo geral, todas as suas versões (apesar de seus pontos em comum e diferenças) tratam-se de diferentes olhares para a linguagem. $\mathrm{O}$ Círculo de Bakhtin manifesta uma filosofia da linguagem, uma maneira peculiar de refletir sobre língua e linguagem. Segundo Brandes (2017), o Círculo de Bakhtin é conhecido como o Círculo de estudos do qual participavam Bakhtin, Volochinov e Medevedev e eles compreendiam "a língua como "radicalmente social"” (BRANDES, 2017, p. 14).

Com o objetivo de encontrar outros respaldos teóricos e dialogar com os resultados de outras pesquisas, promovi uma busca a respeito do tema discursos sobre Análise do Discurso Dialógica e cotas raciais nas universidades públicas, mas quase não encontrei trabalhos que teoricamente se respaldassem na ADD. A maioria dos estudos encontrados refletiam a respeito do tema mencionado por meio da Análise do Discursos de linha francesa ou pela ACD.

Ao contemplar os conceitos que norteiam a $\mathrm{ADD}$, em o livro Os gêneros do discurso de Tzevetan Todorov (1989), o autor introduz e aborda a noção genérica de discurso sobre o conceito de literatura. Para o autor, o discurso "é o acompanhante do conceito funcional de "uso" (da linguagem) (TODOROV, 1989, p. 21). Em Problemas da Poética Dostoiévski, Bakhtin (2013), o próprio Bakhtin retrata alguns conceitos como: o dialogismo entre personagens literários, o monolinguismo do pensamento único, que de certa maneira representa a política de autoritarismo, a polifonia como método discursivo e etc.

Os gêneros do discurso de Mikhail Bakhtin (2016), essa versão brasileira foi organizada em três momentos: os gêneros do discurso, o texto na linguística, na filosofia e em outras ciências humanas e a parte dos anexos, onde encontram-se as traduções das versões resumidas dos textos de Bakhtin "Diálogo I: A questão do discurso dialógico" e "Diálogo II". Nesse livro Bakhtin (2016) explica como funciona o processo de interação entre falante e locutor e como se dá o resultado da compreensão. “A compreensão não repete nem dubla o falante, ela cria sua própria concepção, seu 
próprio conteúdo; cada falante e compreendedor permanece em seu próprio mundo; a palavra faculta apenas o direcionamento, o vértice do cone" (BAKHTIN, 2016, p. 113).

Isto é, conforme a perspectiva de Análise de Discurso Dialógica, a compreensão funciona de tal maneira que a mesma cria a sua própria concepção e conteúdo, falante e locutor continuam em suas posições (falante emite uma mensagem para o interlocutor) e é por meio da palavra que há o direcionamento. Pois segundo Bakhtin (2016), na palavra do falante sempre haverá um elemento apelativo ao ouvinte, que seria uma diretriz voltada para a resposta. "Isto se manifesta com maior clareza no discurso dialógico" (BAKHTIN, 2016, p. 113).

No livro Marxismo e filosofia da linguagem (2017) de Valentin Volóchinov (2017), o autor aborda a importância dos problemas da filosofia da linguagem para o marxismo, como foi o desenvolvimento da filosofia da linguagem; o autor também discute a teoria do enunciado e os problemas de sintaxe (aqui o autor estabelece diálogos com a obra de Émile Benveniste) e questões sobre construções discursivas.

Segundo Volóchinov (2017, p. 204), independente do aspecto da expressão e enunciado, o mesmo" será definido pelas condições reais do enunciado e, antes de tudo, pela situação social mais próxima”, pois conforme o autor, o enunciado é formado entre dois indivíduos socialmente organizados e na ausência de um interlocutor, há a ocupação desse lugar pela imagem do representante médio daquele grupo social, uma vez que a palavra é orientada para um interlocutor, Volóchinov (2017). Essa situação ocorrerá nos dois materiais que propus analisar neste artigo.

Ao aprofundar minhas leituras nas obras mencionadas sobre o círculo de Bakhtin, me foi possível obter a compreensão geral de que na filosofia da linguagem Bakhtiniana há uma abordagem do dialogismo a partir de uma concepção geral da existência e da ação do ser humano, da interdiscursividade e da organização dos textos mobilizados pelos discursos, uma vez que "o diálogo é um fenômeno textual e um procedimento discursivo englobado pelo dialogismo, sendo um de seus níveis mais evidentes no nível da materialidade discursiva" (SOBRAL, 2009, p. 34).

Vasconcelos (2017) e Brandes (2017) também esclarecem que no âmbito do arcabouço de teórico do Círculo de Bakhtin os conceitos centrais de: dialogismo, enunciado, ideologia, linguagem, palavra e signo são formulados e que cada um desses elementos estão ligados uns aos outros, uma vez que:

o enunciado é constituído por palavra, que, por sua vez, é o signo por excelência. $\mathrm{O}$ enunciado é o elo na cadeia da comunicação verbal, de 
forma que entre os enunciados se estabelecem relações dialógicas. $\mathrm{O}$ dialogismo é constitutivo da linguagem e, portanto, dos enunciados que são unidades da comunicação verbal, da linguagem concebida como interação. (VASCONCELOS, 2017, p. 14)

Ou seja, as palavras são signos linguísticos que ao serem utilizadas em conjunto compõem o enunciado, o mesmo por sua vez "é o elo da comunicação verbal" e é por meio dos enunciados é que são estabelecidas as relações dialógicas. Segundo a autora, o dialogismo é algo constitutivo da linguagem e dos enunciados. Portanto, segundo essa noção teórica, os enunciados são concebidos como unidades de comunicação verbal e a linguagem como interação.

Para argumentar ainda mais esse ponto de vista, também trago a reflexão de Brandes (2017), a qual afirma que "Bakhtin e o Círculo, quando falam de linguagem estão falando em interação (...) é também na interação que se constituem as identidades e subjetividades, é também na interação que se dão os diálogos interculturais" (BRANDES, 2017, p. 17).

Ainda de acordo com Vasconcelos (2017), a língua (como um elemento indissociável da linguagem) ao se concretizar nas interação entre os sujeitos, para o Círculo de Bakhtin a língua é inseparável da cultura e das relações sociais.

Não tomamos a língua como um sistema de categorias gramaticais abstratas; tomamos a língua ideologicamente preenchida, a língua enquanto cosmovisão e até como uma opinião concreta que assegura um maximum de compressão mútua em todos os campos da vida ideológica. (BAKHTIN, 2015, p. 40, grifo do autor)

Por essa razão, a ADD se enquadra como fundamento teórico para as reflexões que proponho abordar neste artigo, pois o objeto de estudo que problematizo neste trabalho, os discursos sobre ações afirmativas nas universidades vêm a partir de um fato social, de tal maneira que durante a metodologia deste artigo e nas análises dos dados, buscarei realizar o exercício de olhar para a língua e para a linguagem como dois elementos indissociáveis que manifestam o pensamento dos sujeitos, crenças, discursos e ideologias.

\section{METODOLOGIA}

Neste tópico serão expostos os procedimentos metodológicos desenvolvidos para atingir os objetivos traçados neste trabalho. Conforme fora elencado anteriormente, a metodologia de pesquisa apresenta características de trabalho qualitativo, segue uma perspectiva metodológica interpretativa e descritiva para analisar os vídeos selecionados 
e principalmente envolve conceitos da Análise do Discurso Dialógica como principais instrumentos de análise.

Como meu objetivo principal baseia-se em investigar quais são os principais tipos de discursos, na cosmovisão político ideológica conservadora, que são opositores às políticas de cotas nas universidades públicas brasileiras, para isso precisei pesquisar pelo site do YouTube, o qual pertence ao portal Google e que hoje em dia (afirmarei isso devido a minha própria concepção), o mesmo pode ser considerado uma rede social, pois tanto pessoas físicas como jurídicas, ao serem conectadas à rede do YouTube, podem compartilhar conteúdos e interagirem uns com os outros, tal aspecto que literalmente caracteriza uma rede social. Portanto, pela rede social do YouTube procurei canais de posicionamento político ideológico conservador que abordaram a cosmovisão conservadora a respeito das políticas de cotas nas universidades.

Para concretizar essa busca, primeiramente escolhi trabalhar com o gênero textual mídia áudio visual no formato de vídeo curto, de até 10 minutos de duração, o qual também pode ser considerado um texto, pois segundo Marcuschi (2008), para que um evento comunicativo seja considerado um texto, ele precisa ser:

um tecido estruturado, uma entidade significativa, uma entidade de comunicação e um artefato sociohistórico. De certo modo, pode-se afirmar que o texto é uma (re) construção do mundo e não uma simples refração ou reflexo (MARCUSCHI, 2008, p.72)

Portanto, em nosso atual contexto social e cultural, o vídeo é um tipo de mídia que envolve ao mesmo tempo diversos tipos de recursos sonoros e visuais, que são bastante utilizados na comunicação de grupos sociais a fim de transmitir mensagens específicas. Segundo Gomes (2008), Santos (2015) e Westerkamp e Carissimi (2011) as principais peculiaridades, do que considero como gênero textual vídeo, destaca-se o caráter pedagógico na eficácia de propagar discursos e ideologias. Uma vez que os vídeos no formato de textos áudio visuais atuam diretamente na formação de opiniões e na formação humana, pois nele "há convergência de ações linguísticas, cognitivas e sociais, assim, transmitindo mensagens para os interlocutore" (QUADROS, 2017, p. 63). Portanto, segundo Marcuschi (2008), os gêneros textuais atuam nas relações de poder, como:

atividades discursivas socialmente estabilizadas que se prestam aos mais variados tipos de controle social e até mesmo ao exercício de poder". Portanto, para o autor os gêneros textuais como elemento da linguagem podem ser utilizados dentro de uma esfera discursiva como 
ferramenta de controle social "incontrolável, mas não determinista (MARCUSCHI, 2008, p. 162)

Dos vídeos que selecionei para analisar, segundo Santoro (1989) eles podem ser classificados como "vídeos populares", que conforme o autor, esses tipos de vídeos seriam uma espécie de vídeo produzido por pessoas comuns ou entidades autônomas não vinculadas à mídia ou a canais de televisão, por exemplo. De acordo com autor, a produção de vídeos populares começou a intensificar no Brasil e a ser utilizado por Movimentos Sociais, sindicatos e etc. partir do ano de 1986. De acordo com Santoro (1989) os grupos que geralmente:

(...) trabalham com o vídeo nos movimentos populares possuem projetos bastante diferenciados entre si, e que dependem fundamentalmente da proposta política que orienta a proposta política que orienta o próprio grupo ou entidade com o qual atua (SANTORO, 1989, p. 95).

Escolhi trabalhar com vídeos no desenvolvimento da metodologia, também devido a sua maior eficácia de registro dos fatos, pois o vídeo eficazmente documenta situações melhor do que qualquer outro tipo de documento e também devido à praticidade de o mesmo pode ser encontrado em praticamente todos os tipos de portais, sites, redes sociais e etc., tal aspecto que não deixa de ser o reflexo de nossa atual era de avanços tecnológicos. A respeito desse assunto Sacerdote (2010) argumenta:

$\mathrm{Na}$ atualidade, as tecnologias de informação e comunicação e (TIC) vêm causando transformações em todas as áreas do conhecimento e afetando os ambientes, sociocultural, político, econômico e educacional contemporâneos. As TIC passaram a fazer parte efetiva do cotidiano hodierno. As relações do homem moderno com o mundo estão, de modo crescente, sendo mediadas por recursos tecnológicos. (SACERDOTE, 2010, p. 29)

Ou seja, na atualidade a internet acaba tornando-se praticamente algo inerente em nosso contexto social de comunicação e interação entre os sujeitos. Por essa razão, a fim de ter acesso aos conteúdos que propus problematizar por meio deste trabalho nas mídias áudio visuais, também selecionei um site específico como minha principal fonte de investigação, a rede social YouTube, pois nesse site encontrei mais facilmente alguns tipos de canais que abordam a temática que investigo.

Durante essas buscas encontrei o vídeo intitulado "Cotas Raciais- Luiz Felipe Pondé" ${ }^{3}$ e "Olavo de Carvalho- Cotas raciais fomentam o racismo; Escravidão

\footnotetext{
${ }^{3}$ Disponível em: <https://www.youtube.com/watch?v=w9ah0QeH77I\&t=2s>. Acesso em: 01 abr. 2019.
} 
REVISTA X, Curitiba, volume 14, n.4,p.41-64, 2019

Islâmica"4, nos quais intelectuais que são grandes ícones do conservadorismo no Brasil como Luiz Felipe Pondé que é doutor em Filosofia, escritor, professor e colunista do jornal "Folha de São Paulo" e Olavo de Carvalho, que também é filósofo, escritor, jornalista, conferencista e etc., expõem abertamente seus pontos de vista sobre o sistema de cotas raciais no Brasil.

Como elenquei anteriormente, para analisar os vídeos selecionados irei me respaldar nas ideias do Círculo de Bakhtin, o qual segundo Brandes (2017), não visualiza a língua como um sistema a qual não é tratada de forma abstrata, pois a língua para eles "é mais que um conjunto de regras gramaticais, a língua é interação é discurso, e, portanto, para o Círculo não faz sentido analisar as palavras a partir dessa perspectiva de sistema" morfológico, fonológico e sintático (BRANDES, 2017, p. 18).

Por essa razão, a análise partirá da estrutura da organização do próprio gênero textual vídeo, à medida em que os conteúdos são expostos, a análise dos discursos presentes no vídeo surgirá do conceito de diálogo do Círculo de Bakhtin, buscando refletir sobre os sujeitos, de tal maneira em que o mesmo não seja pensado individualmente:

porque está em constante interação com o outro. Os falantes estabelecem relações dialógicas entre os enunciados e até mesmo enunciados distantes um do outro, seja no tempo ou no espaço, podem ser colocados em relações dialógicas (VASCONCELOS, 2018, p. 21)

Pois como a própria autora elenca, e essa reflexão também dialoga com outras perspectivas de ADs, a linguagem sempre está sobrecarregada de valores e índices sociais e acaba tornando-se palco de disputas de valores e verdades sociais.

\section{ANÁLISE DOS DADOS}

Nesta sessão o primeiro material a ser analisado é vídeo de Luiz Felipe Pondé, o qual está disponível no YouTube, no canal oficial do próprio autor. Até o mês de abril de 2019 esse vídeo alcançou a 187.164 visualizações, 708 comentários (a maioria das pessoas que comentaram o conteúdo do vídeo demonstraram concordar com o conteúdo exposto); o conteúdo obteve 10.000 avaliações positivas e 516 "dislikes" (usuários que demonstraram não gostar do vídeo). Portanto, entre a votação positiva e negativa e pelos

\footnotetext{
${ }^{4}$ Disponível em: <https://www.youtube.com/watch?v=6OY-32qTepc\&t=137s >. Acesso em: 01 abr. 2019.
} 
comentários sobre o vídeo, os internautas, que demonstraram gostar ou concordar com o conteúdo vídeo, são a maioria.

Nesse vídeo Pondé parece estar falando em uma biblioteca particular, ou em uma sala de estudos que parece estar localizada dentro de sua própria residência, pois no espaço em que o locutor está inserido, há uma série de indícios que nos indicam essa possibilidade como: o fato de a linguagem corporal de Luiz Felipe Pondé demonstrar que ele está à vontade, o vestuário dele também demonstra que o locutor está em um ambiente informal e mais familiar. Naquela sala é possível ver duas estantes cheias de livros, em uma dessas estantes há uma fotografia familiar do autor do vídeo.

Ao observar essas características, a partir da escolha do ambiente de onde o locutor fala, é possível destacar que conforme discutimos em nossa fundamentação teórica e no tópico da metodologia, que segundo o Círculo de Bakhtin, Todorov (1989), Bakhtin (2013; 2015; 2016) e Volóchinov (2017), a linguagem nunca é neutra, pois mesmo que inconscientemente, no discurso tudo é intencionado e é colocado em prática por alguma razão.

Ao selecionar o lugar para transmitir a mensagem para os interlocutores, Pondé fez isso com a intenção de causar a impressão de autoridade e credibilidade a respeito do que ele está falando, uma vez que esse vídeo do professor Pondé foi publicado em uma rede social para o público em geral. Ou seja, qualquer pessoa pode ter acesso às informações transmitidas por meio desse vídeo, a própria linguagem que ele utiliza apesar ser bastante formal é acessível para que todas as pessoas o compreendam. Agora analisarei o próximo trecho da articulação de Pondé:

"Eu vou dizer exatamente o que eu penso disso. A princípio... Eu sou contra qualquer forma de critério que não seja o critério do mérito. ” (PONDÉ, 2016)

Nesta parte o locutor afirma ser contra a existência do sistema de cotas no Brasil, porque o tema "políticas de cotas nas universidades" seria sinônimo de ir contra "o critério do mérito". Essa sentença expressaria o discurso e a falsa crença de que os candidatos que tentam vestibular em todas as universidades, que dispõem dessas políticas, pelo sistema de cotas não passassem pelo mesmo processo seletivo que os demais concorrentes que não podem ou não optam pela cota para negros ou estudantes oriundos de escolas públicas.

Pois sabemos que na realidade, em todas as universidades quando há esses tipos de processos seletivos, todos os candidatos, sem exceção, realizam exatamente a mesma prova de conhecimentos gerais no mesmo dia e horário. A única diferença é dentro 
desses processos seletivos, é que dependendo do tipo de curso e da inscrição que o candidato efetua, varia a média de aprovação para a cota social, racial ou universal. Outra diferença é que somente os candidatos autodeclarados negros, em algumas universidades, passam por uma banca de constatação, a qual faz parte do processo de seleção da instituição e que são agendadas individualmente em um dia e horário diferentes da data da prova escrita. Agora observe a próxima colocação do locutor:

"Eu até sou capaz de aceitar a ideia de você ter alguns espaços nas universidades públicas pra alunos vindos do ensino público. Já que o estado ao invés de cumprir sua função que é dar uma boa educação pública. (PONDÉ, 2016)

Nessa parte do vídeo, Pondé (2016) se manifesta a partir de um posicionamento político conservador, o qual assim como na maioria das demais produções intelectuais do autor, como livros, palestras, artigos e etc., ele se manifesta a partir de uma cosmovisão política conservadora "de direita", pois como todos sabemos, a ideologia política classificada como a de "direita" (tal classificação política assim como "esquerda" ou "centro" que considero como uma nomenclatura insuficiente), a qual tradicionalmente significava um conjunto de posturas políticas voltadas para a liberdade. Essa noção básica sobre os valores políticos da direita é bem explicada e criticada em alguns aspectos no livro Educando à Direita de Michel Apple.

É interessante que, primeiramente Pondé apresenta a maioria de sua argumentação e analisa a situação socioeconômica do Brasil por meio de uma cosmovisão conservadora. No entanto, nesse momento do vídeo, no enunciado que acabei de destacar, o locutor se justifica a partir de uma cosmovisão com características "progressista" ou de "esquerda", cujo conjunto de posturas políticas são mais voltados para a equidade econômica e social. É como se ele estivesse negociando o seu conjunto de crenças e valores com os discursos e ideologias opostos ao o que ele acredita, tal aspecto que é possível observar que representa o conceito de dialogismo bakhtiniano, no qual o sujeito dialoga e negocia valores, discursos e ideologias com o mundo exterior a ele.

Pois nesse trecho Podé ressalta qual deveria ser o papel do estado na educação, uma vez que o locutor introduz que diante de uma situação socioeconômica como a do nosso país e ao fato de a educação pública longo de muitos anos vir se degenerando cada vez mais. O locutor demonstra concordar parcialmente com políticas de cotas e a inclusão de estudantes oriundos de escolas públicas em nosso espaço acadêmico, pois como o próprio Luiz Felipe Pondé colocou, é responsabilidade do governo brasileiro, do 
estado oferecer para a população uma educação de qualidade nas escolas públicas, a ponto de que tanto os alunos do ensino público como os de escolas particulares possam concorrer de maneira igualitária a qualquer vaga nas universidades públicas. Na próxima sentença o locutor finaliza o raciocínio expondo:

"Não faz! E depois fica criando subterfúgios pra isso na universidade, que claramente a escola é prioritariamente função do estado e do município, do governo federal que inventa as histórias das cotas”. (PONDÉ, 2016)

Neste trecho é como se o locutor novamente fizesse um câmbio de pensamentos e ideologias políticas e voltasse para a cosmovisão e o discurso de ideologia política de direita, a qual se opõe à esquerda. Essa estratégia discursiva identifico como um recurso retórico de persuasão no momento em que Pondé conclui o período que acabei de analisar, apresentando uma verdade que todos conhecem: o estado realmente não cumpre o seu dever de garantir uma educação de boa qualidade nas escolas públicas, ao ele afirmar, "o estado não faz!".

Depois disso, o locutor manifesta que o governo não fornece suporte para a educação no Brasil, e depois ele "fica criando subterfúgios para isso na universidade". O que seria termo "isso" na universidade? As falhas e fragilidades no nosso sistema de ensino público que não são resolvidas pelo apoio do estado? Depois disso, Pondé complementa no próximo período que: é função do estado, do município e do governo federal garantir boas escolas públicas, só que o governo para não cumprir esse papel, ele cria uma nova demanda que consiste em "inventar as histórias sobre as cotas".

O locutor ao utilizar esse termo "inventar as histórias das cotas", como estratégia linguística e discursiva, ele realiza uma escolha de termos a fim de expressar a ideia de que as cotas são uma "história" invenção do estado, o qual não quer garantir um bom ensino nas escolas públicas, e sem se importar com as consequências disso (se a qualidade da formação profissional dos acadêmicos e graduados em nossas universidades públicas também irá decair cada vez mais), inventam projetos de leis e políticas públicas que não resolvem completamente o nosso problema da educação básica. Agora analisarei o próximo trecho do vídeo:

"Mas independentemente disso, a ideia de cotas raciais me parece uma deia infeliz. Acho melhor se a gente for falar de algum modo de tentar empatar o jogo, é fazer cotas de ensino público, porque nesse espectro você contempla pessoas que vêm de camadas sociais mais vulneráveis economicamente, e mas dentro disso você contempla algum tipo de mérito que percorre o espaço interno das escolas públicas. 
REVISTA X, Curitiba, volume 14, n.4,p.41-64, 2019

Certo? Então você teria alguma noção de mérito resguardada ao lado de uma noção a favor de uma certa proteção de população vulnerável economicamente. Enquanto que as cotas raciais assumem a um critério racialista.” (PONDÉ, 2016)

Como últimos aspectos do vídeo de Pondé (2016), é pertinente destacar que nos últimos minutos da mensagem dele, o locutor finaliza reafirmando e concluindo que "a ideia de cotas", novamente o autor realiza essa seleção discursiva para reafirmar que as políticas de cotas nas universidades não é uma boa realidade. Pois para ele, a alternativa de promoção desse tipo de políticas públicas é assimilado como "algo infeliz", que não traz bons resultados.

No próximo trecho da fala de Pondé (2016), ele expõe que a melhor alternativa para solucionar um pouco os problemas de desigualdade social que existem no Brasil, seria "promover políticas de cotas sociais", as quais são mais voltadas a estudantes que de modo geral são advindos da rede pública de ensino no Brasil. Na concepção dele, isso seria uma maneira mais justa de combate às discriminações, porque de certa forma, além de promover a inclusão de pessoas pertencentes ás camadas sociais mais vulneráveis de nossa sociedade, ao mesmo tempo estaria sendo contemplado "algum tipo de mérito que percorre o espaço interno das escolas públicas” (PONDÉ, 2016).

Ou seja, novamente no discurso do locutor, prevalece a ideologia da meritocracia, como se os negros que tentam vestibular não estivessem sendo aprovados em concursos públicos ou nas universidades públicas em virtude seus próprios méritos e capacidades intelectuais.

Vale ressaltar que o que é contemplado na divisão do sistema de cotas, não é aquela ideologia preconceituosa e os discursos que a muito tempo demarcaram a nossa história proclamando a inferiorização da capacidade intelectual do negro e dos povos africanos, que segundo Guimarães (1995), repercutiu bastante na História do Ocidente e principalmente na História do Brasil, durante todo o período de escravização dos negros até a pós abolição da escravatura no Brasil (esse assunto será parcialmente abordado no segundo vídeo que analisarei neste tópico).

Voltando a analisar os últimos minutos do vídeo de Pondé (2016), vale ressaltar que após o locutor apresentar o raciocínio de que nas universidades públicas brasileiras, deveriam existir somente as cotas destinadas a alunos de escolas públicas, pois estaria sendo ressaltado o mérito e a capacidade intelectual dos estudantes de baixa renda que não tiveram as mesmas oportunidades de quem consegue pagar por um ensino de qualidade durante a educação básica. 
REVISTA X, Curitiba, volume 14, n.4,p.41-64, 2019

Também me foi perceptível que, como estratégia retórica e até mesmo didática, pois após apresentar o seu ponto de vista e "supostamente lecionar sobre o assunto", pois como abordei no tópico da metodologia deste artigo, conforme Sacerdote (2010), Westercamp e Carissimi (2011), Santos (2015), Mandarino (2002) e Gomes (2008), o vídeo popular apresenta características e objetivos pedagógicos, o qual segundo Santoro (1989), ao ser popularizado ao longo da América Latina e especificamente no Brasil, após o período da ditadura militar, a produção de vídeos passou a ser bastante utilizada por sindicatos, entidades não governamentais, grupos sociais e pessoas, não necessariamente vinculadas à mídia televisiva, os quais se valiam da utilização da mídia áudio visual como produção e documentação de conhecimento, a fim de propagar discursos e ideologias.

Agora analisarei alguns dos principais trechos do vídeo intitulado "Olavo de Carvalho- Cotas raciais fomentam o racismo; Escravidão Islâmica”, de duração de dez minutos. Esse vídeo até o mês de abril de 2019 alcançou a 45.773 visualizações, obteve 155 comentários (os quais a grande maioria ou a totalidade demonstraram apoiar e concordar com o conteúdo do vídeo). Esse material teve 2.700 avaliações positivas e 62 avaliações negativas, portanto houve uma desproporcionalidade discrepante na comparação da votação de quem gostou e quem não aprovou o conteúdo do vídeo. Assim como o material publicado por Pondé (2016), o vídeo de Olavo de Carvalho também é aberto ao público em geral.

No entanto, encontrei esse material disponibilizado no canal um outro usuário do YouTube, o qual não é o canal oficial do próprio autor do vídeo. Na descrição, esse usuário esclarece que o vídeo foi extraído do site oficial de Olavo de Carvalho, o "True Outspeak", esse vídeo foi publicado em maio de 2012 e os outros links, que também podiam acessar a esse vídeo, foram disponibilizado na descrição.

É relevante ressaltar que a primeira característica que mais me chamou atenção nesse vídeo é o seu título, pois o mesmo expressa exatamente o assunto que foi abordado por Olavo de Carvalho, pois durante o vídeo inteiro e principalmente no final, o locutor manifesta que a sua opinião sobre as cotas é a de que essas políticas públicas no Brasil "fomentam ainda mais o racismo". Assim como ele expõe no trecho a seguir:

“Também, aqui a Miriam Macedo publicou no blog dela um texto de 8 linhas dizendo o seguinte: dizendo que com esse negócio de cota, isso aí vai criar uma desconfiança, uma suspeita em torno de profissionais negros, porque você vai pensar aí: "Não! Esse Doutor aí ele é "da cota!”. O cara é dentista, médico. Você já vai ficar 
REVISTA X, Curitiba, volume 14, n.4,p.41-64, 2019

aí né! Desconfiada, quer dizer, antes não fazia a menor diferença de ser preto, branco, amarelo, azul, verde com bolinhas. Você não ligava, o que interessava era a competência. Tá certo? Mas agora o sujeito já vem com o cartaz dizendo: "Sou da Cota! ”. P*! Isso aí desmoraliza qualquer um! Isso aí é verdade! A Miriam falou uma coisa que é absolutamente inegável. Isso aí vai criar uma certa prevenção contra os profissionais negros! Que é uma coisa injusta. Tá certo?! Mas que vai criar, vai.” (CARVALHO, 2012).

Neste trecho do pronunciamento de Olavo de Carvalho, ele cita como argumentação que os profissionais negros podem sofrer discriminação por haverem ingressado no ensino superior por meio das políticas de cotas. Lembrando que as políticas de cotas são políticas públicas de ações afirmativas temporárias e não permanentes, apenas de ingresso no ensino superior (QUADROS, 2017). Portanto, vale ressaltar que a partir do momento em que o aluno se insere no espaço acadêmico, ele terá o mesmo rigor de exigências nos estudos e a mesma formação que os demais alunos não cotistas. Tanto é que há vários estudos acadêmicos como os de Andrade (2010), Iensue (2009), Plá (2009), entre tantos outros autores, os quais com suas peculiaridades narram os desafios e as superações das dificuldades de adaptação dos estudantes cotistas no espaço universitário e os resultados positivos da implementação do sistema de cotas nas universidades públicas brasileiras.

No trecho do pronunciamento do professor Olavo de Carvalho que destaquei também é possível observar que o locutor, como estratégia discursiva de argumentação, constrói o seu discurso se baseando no texto de uma outra pessoa que compartilha a mesma opinião que ele, pois assim é transmitida a seguinte mensagem para o interlocutor: "Eu não sou a única pessoa que está afirmando isso!", a fím e sustentar a argumentação de que as cotas instigam ainda mais o racismo.

Também interessante que como estratégia linguística e discursiva o Olavo de Carvalho utiliza o recurso da ironia quando ele afirma que: "antes não fazia a menor diferença de ser preto, branco, amarelo, azul, verde com bolinhas" (CARVALHO, 2012), para o autor elencar que antes o que realmente importava era a competência do profissional independentemente da cor de sua pele.

Vale destacar que assim como constatei em minha pesquisa de mestrado, ao analisar os discursos, ideologias, embates e as contradições que repercutiram durante o processo de análise das políticas de cotas na UEPG, observei que o discurso e a crença de que as cotas para negros fortalecem ainda mais o racismo, e que a mesma é por si só 
uma forma de discriminação contra os negros, foi um dos principais argumentos utilizados por parte de alguns Conselheiros durante a reunião do Conselho Universitário, para a retirada das cotas para negros da universidade.

Portanto, é possível argumentar que assim como Círculo de Bakhtin propõe e a própria ACD também argumenta, que de modo geral, a opinião pública a respeito de todo o tipo de assunto é modificada a partir de uma construção sócio- histórica e por intermédio da intertextualidade, uma vez que as opiniões dos sujeitos são construídas com base na influência de outros tipos de discursos que repercutem socialmente. Um exemplo disso no vídeo é o momento em que o professor se baseando no texto de outra pessoa, constrói a sua argumentação e depois disso, o locutor cita e compara fatos históricos a respeito do processo de escravização tanto no Ocidente como Oriente, mencionando principalmente a cultura de escravização islâmica:

"Quando acabou a escravidão no Brasil não havia emprego para a grande massa de ex escravos, simplesmente não havia. Você não pode esquecer que a liberação dos escravos foi no final do século XIX, a industrialização no Brasil só começou na década de 30.

Quer dizer... Os caras tiveram 40 anos para procriar sem ter emprego, meu Deus do céu! Sem ter emprego! Não tinham onde morar! De onde que você acha que foi a origem das favelas, as favelas foi isso! Então os caras não tinham mais lugar nas cidades, então os caras se ajeitaram lá no morro. Então 40 anos. Olha é muita gente que surgiu! Tá certo?! Então a sociedade não tinha como absorver esta mão e obra.

E só muito gradativamente, a industrialização brasileira não foi essas mil maravilhas! Teve um impulso na década de 30, outro na década de 60 (....). É claro que ficou esta deformidade na sociedade brasileira. Essa deformidade não foi implantada por lei. Não foi ninguém que disse: Nós só vamos dar emprego pra brancos. No Brasil não existem leis discriminatória! Mas tem uma discriminação econômico social, que é fruto da própria formação errada. Que quer dizer: "Quem mandou o Brasil ter escravos?" O Brasil foi um dos países mais escravagistas do mundo. Pra competir com o Brasil, só o pessoal do mundo islâmico! Que fazem campanha contra o Ocidente, dizendo que o Ocidente é campeão no escravagista." (CARVALHO, 2012)

Depois disso, o Olavo de Carvalho começa a fazer comparações entre a escravização histórica no Ocidente e a escravidão islâmica no Oriente (a qual ainda existe até nos dias de hoje de forma legalizada em alguns países árabes, uma prova disso são as inúmeras reportagens, documentários, livros e etc. que denunciam fatos sobre a 
existência da escravização principalmente das mulheres nesses países). Neste momento é como se o locutor estivesse fazendo um concurso para conferir qual dos dois sistemas escravagistas foi o mais cruel, mencionando: os tipos de mortes dos escravizados durante o tipo de transporte utilizado, quem escravizava mais homens ou mulheres, a castração dos homens escravizados e a cultura da escravização sexual das mulheres nos países islâmicos.

Portanto, apesar de o foco principal discutido no vídeo fosse ações afirmativas para negros no sistema educacional brasileiro, como esse complexo assunto está relacionado ao processo histórico de escravização dos negros africanos no contexto específico brasileiro, o Olavo Carvalho acabou tocando no assunto escravização em âmbito universal, citando tanto o tema escravização no Ocidente como no Oriente.

Só que o que estava sendo avaliado no vídeo, era o contexto social do Brasil na atualidade e não o mundo árabe. É como se a mensagem transmitida para o interlocutor fosse: os países de cultura islâmica ainda são escravagistas, principalmente, porque alguns radicais escravizam sexualmente as mulheres. Então, vejam! Existem lugares no mundo onde a situação é muito pior do que no Brasil. Portanto, mesmo após Olavo de Carvalho ter apresentado uma série de fatos verídicos relacionados a história do Brasil, dos negros no país, por meio da citação e análise desses fatos; ele ter comprovado que realmente existe discriminação racial com profundas raízes históricas no Brasil. O locutor ainda não consegue enxergar que existem várias razões para a promoção de políticas de cotas nas universidades brasileiras, por exemplo.

Quanto ao espaço de onde Olavo de Carvalho fala, vale ressaltar que a sala é parecida com a sala de onde Pondé (2016) também gravou o seu vídeo, é uma sala cheia de livros, a qual expressa características de intelectualidade, leitura e estudos, cujo lugar específico presumimos que também foi escolhido intencionalmente.

Outra característica importante é que esse vídeo não foi gravado no Brasil, pois Carvalho a muitos anos não vive mais aqui, mas sim nos Estados Unidos. Ou seja, tratase de um sujeito que desde muitos anos e atualmente vive em um outro país completamente diferente do seu país de origem (principalmente quando se trata de nuances socioeconômicas). A partir disso Olavo de Carvalho faz algumas comparações políticas entre o Brasil e os Estados Unidos, o qual é um país que diferentemente do Brasil, é considerado o berço das políticas de ações afirmativas, Santos (2007) e Andrade (2010). No entanto, o locutor durante vários momentos no vídeo critica as políticas de ações afirmativas no Brasil, mas nunca fala mal dos Estados Unidos. 
REVISTA X, Curitiba, volume 14, n.4,p.41-64, 2019

Conforme mencionei no tópico anterior, tanto Luiz Felipe Pondé como Olavo de Carvalho, ambos são dois filósofos, professores, palestrantes, jornalistas, escritores e intelectuais conservadores brasileiros de direita, que atualmente em âmbito nacional e internacional divulgam por meio de suas obras: valores e ideologias políticas de matriz conservadora, nas quais eles acreditam.

Por essa razão, escolhi analisar a esses vídeos específicos de ambos os locutores, devido à característica subjetiva de ambos os materiais, para assim cumprir o objetivo geral deste trabalho, o qual consiste em investigar quais são os principais tipos de discursos, na cosmovisão político ideológica conservadora, que são opositores às políticas de cotas nas universidades públicas brasileiras, me respaldando no Círculo de Bakhtin e encontrando indícios de que não se pode pensar em língua, discursos e ideologias sem observar aspectos sociais e a sociedade.

\section{CONSIDERAÇÕES FINAIS}

Durante as análises ao buscar refletir no tópico da fundamentação teórica, pautando-me nas ideias centrais do Círculo de Bakhtin, Todorov (1989), Bakhtin (2013; 2015; 2016) e Volóchinov (2017), a respeito da relação entre a língua e interação social e da não neutralidade dos discursos que nos rodeiam. Me foi possível alcançar os objetivos estabelecidos neste estudo, os quais foram atingidos à medida em que fui percorrendo um percurso metodológico, o qual envolveu pesquisa qualitativa, descritiva e interpretação dos dados coletados.

Conforme descrevi no tópico da metodologia, selecionei pela rede social do YouTube dois vídeos específicos acerca do tema políticas de ações afirmativas para negros nas universidades públicas brasileiras, nos quais intelectuais conservadores de direita expressaram suas opiniões e analisaram o tema a partir de uma cosmovisão conservadora de direita. A partir disso, pude identificar quais eram os principais tipos de discursos, na cosmovisão político ideológica conservadora opositores às políticas de cotas em nossas universidades.

Ao analisar os vídeos de Luiz Felipe Pondé e de Olavo de Carvalho, encontrei uma série de discursos e ideologias contraditórios às políticas de cotas em nossas universidades, como por exemplo: o discurso da meritocracia; cotas fomentam ainda mais o racismo; "como pode haver políticas de cotas raciais em uma sociedade em que mais de 50\% da população é negra?”; “o processo de escravização dos negros africanos para o Ocidente foi menos violento e cruel que a escravização islâmica no Oriente"; "a 
luta pelo direito às cotas nas universidades é puramente fruto da ganância do Movimento Negro, porque na verdade o que eles querem é poder! ", (nem todos esses discursos que foram citados puderam ser analisados no vídeo de Olavo de Carvalho no tópico das análises, pois a análise crítica daria uma extensa monografia. No entanto, destaquei os principais momentos das articulações dos autores de ambos os vídeos analisados neste artigo). É notável que alguns dos discursos que analisei perduram em nossa sociedade, alguns deles foram identificados e desconstruídos em recentes pesquisas que buscaram avaliar a realidade do contexto de ingresso e permanência de estudantes cotistas nas universidades em várias pesquisas que fazem minuciosas investigações em diversas IES espalhadas por todo o Brasil.

É pertinente ressaltar que encontrei na Análise do Discurso Dialógica uma interessante e rica fonte teórica e metodológica, a qual pode oferecer eficazes aparatos e possibilidades de análise ao analista de discursos, em virtude das características desse campo teórico. Portanto, nas falas que destaquei nas análises deste artigo, é possível expandir em outros trabalhos diversificadas possibilidades de reflexões, principalmente pensando-se na questão sobre como os sujeitos dialogam internamente as suas crenças e ideologias, as negociam com as ideologias e discursos externos que sejam opostos aos seus valores morais propagados, Bakhtin (2013; 2016), Todorov (1980) e Volóchinov (2017).

Um exemplo disso foi aquele momento de um dos vídeos, em que o professor Luiz Felipe Pondé, mesmo sendo um militante conservador de direita, ele declara concordar parcialmente com algumas ideias que parecem ser progressistas, de esquerda. A partir daí, eu trago a discussão baseando-me em Apple (2003), que os parâmetros que definem as matrizes políticas ideológicas de esquerda ou de direita são insuficientes para definir integralmente cada ideologia política. Ou isso seria a questão da negociação? A qual é uma tese apresentada pelo Círculo de Bakhtin. Essa é também uma outra lacuna a ser preenchida por futuras pesquisas interdisciplinares que surjam dentro do campo da ADD ou nas "Análises de Discursos", Paula (2013) que por si é uma área bastante vasta e propensa a ser interdisciplinar, uma vez que a mesma busca desmistificar por meio dos discursos, que é o seu objeto de estudo, a relação entre homem e sociedade, Orlandi (2002).

Por fim, vale ressaltar que devido ao nosso atual contexto, de inúmeras mudanças no cenário político do Brasil, com o crescente número de simpatizantes da ideologia política conservadora de direita, a qual atualmente tornou-se bastante forte no 
cenário político e social do país, visando o papel das redes sociais, e principalmente, pela influência dos discursos propagados por meio da rede social do YouTube, que é bastante popular no Brasil (por isso escolhi esse site específico como fonte para a coleta de dados).

Nesse contexto social torna-se fundamental discutir os tópicos que apresentei neste trabalho, sobretudo o que ambas as ideologias políticas independentemente de ser de esquerda, direita ou centro, argumentam acerca de minorias que englobem: raça, sexualidade, gênero, classe social, pessoas portadoras de necessidades especiais; colônias de imigrantes e etc.; ações afirmativas na sociedade; direitos civis; políticas públicas e etc. Quais são os seus discursos? Acredito que todas as "Análises de Discursos", Paula (2013), e suas ramificações: AD Francesa, a Análise Crítica do Discurso, ADD, as ADs semióticas de linha inglesa e norte-americana, russa e francesa, e as teorias enunciativas de Benveniste podem nos auxiliar a encontrar e a interpretar as respostas que precisamos.

\section{REFERÊNCIAS}

ANDRADE, P. H. de. As ações afirmativas na UEL: um estudo sobre a sociabilidade dos estudantes negros na universidade. 2010, 126f. Dissertação (Mestrado em Ciências Sociais) - Universidade Estadual de Londrina, Londrina, PR, 2010.

APPLE, M. Educando à Direita. 1 ed. São Paulo: Cortez, 2003. 304p.

BAKHTIN, M. Diálogo I A questão do discurso dialógico. In: BAKHTIN, M. Os gêneros do discurso. Organização, tradução, posfácio e notas de Paulo Bezerra; notas da edição russa de Serguei Botcharov. 1 ed. São Paulo: Editora 34, 2016. p. 133-124.

BAKHTIN, M. Problemas da Poética de Dostoiévsky. Tradução direta do russo, notas e prefácio de Paulo Bezerra. 5 ed. Rio de Janeiro: Forense Universitária, 2013. 366 p.

BAKHTIN, M. Teoria do romance I: a estilística. Tradução, prefácio, notas e glossário de Paulo Bezerra; organização da edição russa de Serguei Botcharov e Vadim Kójinov. 1. ed. São Paulo: Editora 34, 2015. 256 p.

BRANDES, S. Diálogos interculturais na literatura indígena contemporânea: uma perspectiva bakhtiniana. 2017, 131f. Dissertação (Mestrado em Estudos da Linguagem) - Universidade Estadual de Ponta Grossa, Ponta Grossa, PR, 2017.

COTAS Raciais- Luiz Felipe Pondé. Gravação de Luiz Felipe Pondé. São Paulo, Brasil, 2016. Vídeo (2min11seg), 2016. Disponível em:

<https://www.youtube.com/watch?v=w9ah0QeH77I >. Acesso em: 01 abr. 2019. 
GOMES, L. F. Vídeos didáticos: uma proposta de critérios para análise. Revista Brasileira em Estudos Pedagógicos. Brasília, v. 89, n. 223, p. 477- 492, set./dez., 2008.

GUIMARÃES, Antônio Sérgio Alfredo de. Racismo e anti-acismo no Brasil. Revista Novos Estudos. São Paulo, n.43, p. 23-44, nov. 1995.

IENSUE, G. Politica de cotas raciais em universidades brasileiras: entre a legitimidade e a eficácia. 2009, 295f. Dissertação (Mestrado em Ciências Sociais e Aplicadas) Universidade Estadual de Ponta Grossa, Ponta Grossa, PR, 2009.

MANDARINO, M. C. F. Organizando o trabalho com vídeo em sala de aula. Revista Eletrônica em Ciências Humanas. Pindamonhagaba, SP, v. 1, n. 1, 2002.

MARCUSCHI, L. A. Gêneros textuais no ensino de língua. In: MARCUSCHI, L. A. Produção Textual, Análise de gêneros e compreensão. São Paulo: Parábola, 2008. cap.2. p. 145-226.

OLAVO de Carvalho Cotas raciais fomentam o racismo; Escravidão islâmica. Trecho retirado do True Outspeak. Produzido por Olavo de Carvalho. Richmond, Virgínia, Estados Unidos, 2012. Vídeo (10min18seg). Disponível em:

$<$ https://www.youtube.com/watch?v=6OY-32qTepc>. Acesso em: 1 abr. 2019.

ORLANDI, Eni Pucinelli. I. O Discurso. In: ORLANDI, Eni Pucinelli.. Análise de discurso: princípios e procedimentos. Campinas, SP: Pontes, 4. ed. 2002. p. 15- 20.

PAUlA, L. de. Círculo de Bakhtin: uma Análise Dialógica do Discurso. Revista Estudos da Linguagem. Belo Horizonte. v. 21, n. 1, p. 239- 258, jan./jun. 2013.

PLÁ, S. Os cotistas negros na universidade: perfis e representações. 2009, 167f. Dissertação (Mestrado em Educação) - Universidade Estadual de Ponta Grossa, Ponta Grossa, PR, 2009.

QUADROS, D. F. M. Discurso e poder: um olhar acerca das ações afirmativas na UEPG em 2013. 2017, 231f. Dissertação (Mestrado em Estudos da Linguagem) Universidade Estadual de Ponta Grossa, Ponta Grossa, PR, 2017.

SACERDOTE, H. C de S. Análise do vídeo como recurso tecnológico educacional. Rev. REVELLI. Inhumas, GO, v. 2, n. 1, p. 28-37, mar., 2010.

SANTORO, L. F. A imagem nas mãos: o vídeo popular no Brasil. São Paulo: Summus Editorial, 1989. 137 p.

SANTOS, M. P. dos. Vídeo didático como tecnologia audiovisual: antecedentes históricos e implicações pedagógicas-metodológicas. Revista Educação Cultura e Sociedade. Sinop, MT, v. 5, n. 1, p. 83-106, jan./jun. 2015.

SOBRAL, A. Do dialogismo ao gênero: as bases do pensamento do círculo de Bakhtin. Col. Ideias sobre linguagem 1. ed. Campinas: Mercado das Letras, 2009. 176 p.

TODOROV, T. Os gêneros do discurso. Tradução de Elisa Agnotti Kossovitch. São Paulo: Martins Fontes, 1980. 305 p. 
VASCONCELOS, E. P. Os discursos dos candidatos a presidente da república no pleito de 2014 em uma perspectiva bakhtiniana. 2017, 121f. Dissertação (Mestrado em Estudos da Linguagem) - Universidade Estadual de Ponta Grossa, Ponta Grossa, PR, 2017.

VOLÓCHINOV, V. Parte II- Os caminhos da filosofia da linguagem marxista. In: VOLÓCHINOV, V. Marxismo e filosofia da linguagem: Problemas fundamentais do método sociológico na ciência da linguagem. Tradução, notas e glossário de Sheila Grillo e Ekaterina Vólkova Américo. 1. ed. São Paulo: Editora 34, 2017. p. 143- 225.

WESTERKAMP, C.; CARISSIMI, J. VÍDEOS INSTITUCIONAIS: Uma análise comparativa. In: 12 Congresso de Ciências da Comunicação na Região Sul, 12., 2011. Anais do XII Congresso de Ciências da Comunicação na Região Sul. Londrina, PR: Sociedade Brasileira de Estudos Interdisciplinares da Comunicação - Intercom, 2011. p. $1-15$. 